\title{
热带季节雨林林窗边缘不同热力作用面热力 效应的季节变化特征
}

\author{
荬军霞 ${ }^{1}$ 张一平 $^{1}$ 马友荃金 ${ }^{1}$ 刘玉洪 ${ }^{1}$ 郭 萍 $^{1}$ 王进欣 ${ }^{2}$ \\ 1 (中国科学院西双版纳热带植物园昆明分部, 昆明 650223) \\ 2 (徐州师范大学城市环境科学系, 徐州 211029)
}

摘要：通过对热带季节雨林雾凉季和湿热季昼间林窗区域不同热力作用面的热力效应初步分析，指出在西双版纳， 不论是雾凉季还是湿热季, 热带季节雨林林窗边缘壁面均具有不可忽视的热力作用, 且由于受林缘树木的影响, 热 力效应较强的东侧、北侧林缘壁面最大区域出现位置高于次生林林窗, 而强度小于次生林林窗。显示了林窗边缘 壁面的热力效应除与太阳高度角、太阳辐射的时间长短和强度有关之外，林窗边缘树木高度也是不可忽视的因子。 其结果可为进一步研究林窗小气候形成机制提供研究基础, 为研究林窗更新及生物多样性问题提供科学参考。 关键词：热带季节雨林，林窗，林窗边缘林墙壁面，热力作用面，西双版纳

中图分类号:Q948,S718.5 文献标识码：A＼cjkstart文章编号 : 1005-0094(2001)04-0366-07

\section{Characteristics of thermal effects and seasonal variation on different ther- mal active surfaces of canopy gaps in tropical seasonal rain forest}

DOU Jun-Xia ${ }^{1}$, ZHANG Yi-Ping ${ }^{1}$, MA You-Xin ${ }^{1}$, LIU Yu-Hong ${ }^{1}$, GUO Ping ${ }^{1}$, WANG Jin-Xin ${ }^{2}$

1 Xishuangbanna Tropical Botanical Garden, Chinese Academy of Sciences, Kunming 650223

2 Department of Urban and Environmental Science, Xuzhou Normal University, Xuzhou , Jiangsu 211029

\begin{abstract}
Based on the analyses of daytime thermal effects of different thermal active surfaces in canopy gaps in tropical seasonal rain forest in the cool-fog and hot-wet season in Xishuangbanna, the thermal characteristics of different thermal active surfaces in canopy gaps are described. The finding showed that : The thermal effect of vertical thermal active surfaces is not negligent, not only in the cool-fog season, but also in the hot-wet season. Moreover, influenced by the height of trees that form the edge of the gap , the height of maximum area of thermal effect of vertical thermal active surfaces at the east and north edge of gaps in tropical seasonal rain forest was higher than that in secondary forest, but the intensity of thermal effects was weaker, compared to secondary forest. This indicates that, besides solar angle, time and intensity of radiation, the height of trees is also an important factor that influences thermal effects of vertical thermal active surface of edges. The results supply a research basis for understanding microclimatic formation of canopy gaps, for studying forest succession and effects of forest biodiversity.
\end{abstract}

Key words : tropical seasonal rain forest, canopy gap , vertical thermal active surface of edges , thermal active surface, Xishuangbanna

\section{1 引言}

林窗是森林生长循环过程中必不可少的阶段之 一( Watt, 1947； Whitmore, 1978, 1989,1990)。因为
林窗的出现, 造成了森林内的温度变化程度 (日较 差和年较差) 比林外小以及林内夜暖昼凉和冬暖夏 凉的热力特征发生改变 (王正非等, 1985;翁笃鸣

基金项目：云南省自然科学基金项目 (98C098M)、国家自然科学基金项目 (39770141)、中国科学院 九五”重大项目 (KZ951-A1-104-01)和中国 科学院院长基金部分研究结果。 
等,1981) ,而这些变化将引起土壤理化性质、营养 元素的分解、土壤微生物的活性等环境因子发生相 应的变化 (Brown,1993)，从而导致林窗环境的异质 性。林窗微环境在森林种群动态方面扮演着重要角 色( Bazzaz \& Wayne,1994 ;Brokaw,1985 ;Canham et al. 1990;Clark, 1990;Denslow,1980)，它对繁殖体 的传播、种子萌发、幼苗生存、树木生长、植物的构型 和繁殖以及物种的多度和丰富度都起着重要作用 ( Connell, 1989 ;Brokaw \& Scheiner,1989 ;Schupp et al. 1989 ;Runkle,1982)。在林窗环境异质性中，对 于林窗的小气候环境方面已有了一些报道 (Brown， 1993 ;藏润国等,1999; 张一平等,1999 ;王进欣等， 1999) 但这些研究都局限于对光、温、湿等环境因 子在水平方向的时空变化上,忽略了林窗作为一个 立体空间,其垂直方向上也存在环境异质性问题。 张一平、王进欣等 (2000,2001) 曾对西双版纳热带 次生林林窗的边缘壁面热力效应进行过初步研究, 指出林窗边缘的热力效应不可忽视, 其热力作用在 尽间某些时候甚至大于林窗中央地表面。鉴于热带 季节雨林的重要地位和作用, 对其林窗不同热力作 用面，特别是林窗边缘壁面的热力特征的研究就显 得十分重要, 这将有助于解决林窗边缘壁面的热力 效应是否普遍存在、受哪些因素影响、是否存在热力 特征时空变化的普遍规律等一系列问题, 并能为林 窗更新、林窗小气候形成机制和林窗内生物多样性 等问题提供科学依据。

\section{2 研究地概况与研究方法}

\section{1 研究地概况}

西双版纳位于云南省南部，终年受西南季风控 制, 属热带季风气候，一年中有雾凉季(11月～次年 2 月)、干热季 ( 3 月 $\sim 4$ 月) 和湿热季 ( 5 月 $\sim 10$ 月) 之分 (张克映,1966)。在雾凉季晴天较多,雾浓且 维持时间长，一般夜间 22 时后逐渐起雾, 到次日中 午 12 时后才逐渐消散。湿热季本地区仍有雾出现， 但是相对雾凉季来说, 其浓度较弱, 起雾较迟( 0 时 前后) 消散较早 (10 时前后); 并且阵性降水日较 多，几乎每天下午 15 时前后均出现降水。

本次观测的样地位于云南省西双版纳州预腊县 预仑镇的热带季节雨林自然保护区内 $\left(21^{\circ} 57^{\prime} \mathrm{N}\right.$ 、 $101^{\circ} 12^{\prime} \mathrm{E}$, 海拔 $756 \mathrm{~m}$ )。雨林群落高度一般为 $30 \sim$ $40 \mathrm{~m}$, 结构复杂, 分层现象明显。乔木层即可分为三
层:上层优势种主要为千果榄仁 (Terminalia myriocarpa)、番龙眼 (Pometia tomentosa), 中下层类型主 要是云南玉苮 (Barringtonia macrostachya)、细罗伞 (Ardisia tenera)、窄序岩豆藤 (Millettia leptobotrya) 等 ( 任泳红等,1999)。

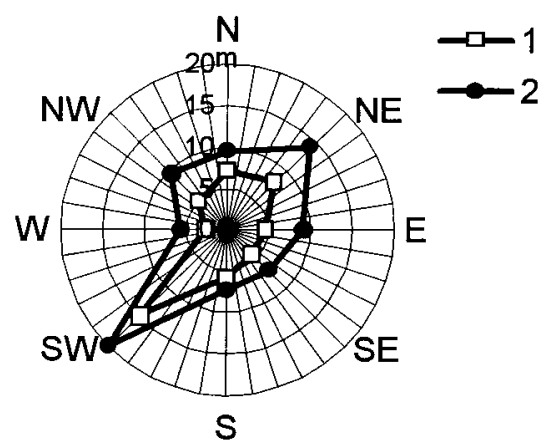

图 1 热带季节雨林林窗轮廓

1. 实际林窗边缘 ; 2 . 扩展林窗边缘

Fig. 1 The outline of tropical seasonal rain forest canopy gap 1. The edge of gap $; 2$. The edge of extended gap

\section{2 研究方法}

本文所选择的林窗是 1997 年掘根倒木形成。 该林窗东北 - 西南向长 (约 $34 \mathrm{~m}$ ) ,东南 - 西北向短 (约 $18 \mathrm{~m}$ ) , 近似纺锤形。轮廊图的内圈线为实际林 窗边缘 (林窗边缘树冠垂线处), 外圈线为扩展林窗 边缘 (林窗边缘树干处)。实际林窗的面积约 116 $\mathrm{m}^{2}$,扩展林窗面积约 $449 \mathrm{~m}^{2}$ 。林窗边缘树木 (观测 样木) 的高度为: 东侧 $22 \mathrm{~m}$, 北侧 $26 \mathrm{~m}$,西侧 $32 \mathrm{~m}$, 南侧 $32 \mathrm{~m}$ 。

在林窗中沿 S-N、E-W 设置 2 条观测样线, 每条 样线设置 7 个观测点, 考虑到边缘效应的作用, 观测 点为不等距分布, 分别位于林窗中央、实际林窗边 缘、扩展林窗边缘和林内。观测要素为地上 $1.5 \mathrm{~m}$ 高处最高、最低气温和气温 (最高、最低温度表), 光 照( 数字式照度计) 以及地表面温度。在林窗边缘 的东 $(E)$ 、南 $(S)$ 、西 $(W)$ 、北 $(N)$ 侧 (以林窗中央为 基准，下同) 和林内观测了树干不同高度 ( $0 \mathrm{~m} 、 0.5$ $\mathrm{m} 、 1 \mathrm{~m} 、 2 \mathrm{~m} 、 4 \mathrm{~m} 、 8 \mathrm{~m} 、 12 \mathrm{~m} 、 16 \mathrm{~m} 、 20 \mathrm{~m}$ 、林冠下) 的 表面温度(红外辐射温度计,COMPAC3 ,日本国 Minolta 株式会社)。观测在 1998 年 12 月 19 20 日的 $9 \sim 17$ 时及 1999 年 7 月 25 日和 10 月 $14 \sim 15$ 日的 $8 \sim 18$ 时进行, 每小时整点观测一次。

本文乃是利用各观测点的地表面温度以及 4 方 位林窗边缘和林内不同高度树干表面温度昼间观测 值，对林窗区域不同热力作用面的热力特征进行分 
析所得的初步结果。

\section{3 结果与分析}

由于西双版纳地区雾凉季和湿热季的气候状况 有较大差异,所以将观测资料分为雾凉季 (1998 年 12 月 ) 和湿热季 (1999 年 7 月和 10 月平均) 进行分 析。

\section{1 树干表面温度的时空分布}

3.1.1 林窗边缘树干表面温度的时空分布 热带 季节雨林 4 方位林窗边缘树干表面温度时空分布如 图 2 所示。可见在雾凉季,由于受浓雾的影响，上午 12 时前，4方位林窗边缘树干表面温度随着树干高 度增加变化不明显, 并且随时间的推移增温幅度也 不大。各方位间的差异也不大。上午 12 时后, 雾散 日出, 随着太阳辐射的增强, 不同方位林窗边缘树干 表面温度的垂直分布表现出明显差异。受太阳直接
照射的东侧边缘, 在树干 $8 \mathrm{~m}$ 及 $20 \mathrm{~m}$ 附近出现表面 温度高值区, 树干 $8 \mathrm{~m}$ 处的温度最大值为 $18.8^{\circ} \mathrm{C}$ (15 时) $20 \mathrm{~m}$ 处为 $19.8^{\circ} \mathrm{C}$ ( 15 时)。太阳直接照射 的北侧边缘, 以树干 $12 \mathrm{~m}$ 处为中心, 形成表面温度 高值区, 温度最高值为 $18.9^{\circ} \mathrm{C}(14$ 时)。林窗南侧 和西侧边缘基本上没有太阳的直接照射，树表温低 于受太阳直接辐射的林冠, 并且树冠所获得的热量 向下传递, 因而在林窗南侧和西侧边缘形成逆温分 布, 最大值出现在林窗边缘壁面上层。

湿热季 4 方位树表温时空分布规律与雾凉季相 似(图 3 ), 上午 12 时前 4 方位树表温随高度变化较 小。上午 12 时后, 受太阳直接照射的东侧、北侧林 窗边缘树干表面形成温度高值区。其中, 东侧边缘 的表面温度高值区出现在树干 $8 \sim 12 \mathrm{~m}$ 处和 $20 \mathrm{~m}$ 附近, 温度最高值分别可达 $28.0^{\circ} \mathrm{C}$ ( 15 时) 和 $27.5^{\circ} \mathrm{C}(15$ 时) ; 北侧边缘则以树干 $8 \mathrm{~m}$ 和 $20 \mathrm{~m}$ 处

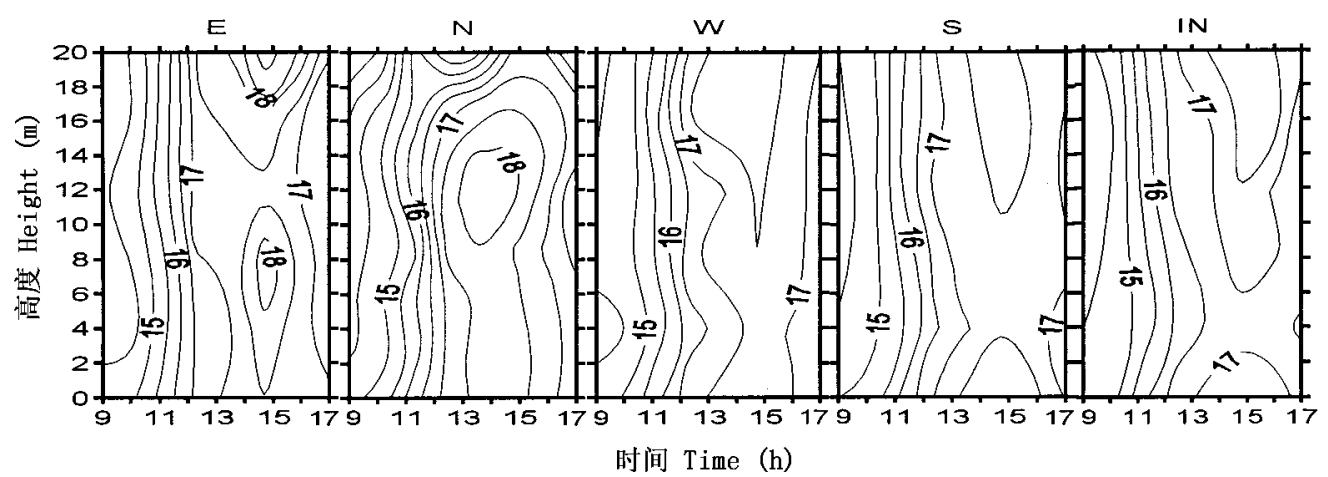

图 2 雾凉季林窗边缘及林内树表温时间变化

$\mathrm{E}$ : 东侧 ; N : 北侧 ; W : 西侧 ; S : 南侧 ; IN : 林内

Fig. 2 Temporal variation of trunk surface temperature at the edge of gaps and in the interior of the forest in the cool-fog season E : East edge ; N : North edge ; W : West edge ; S : South edge ; IN : Interior of forest

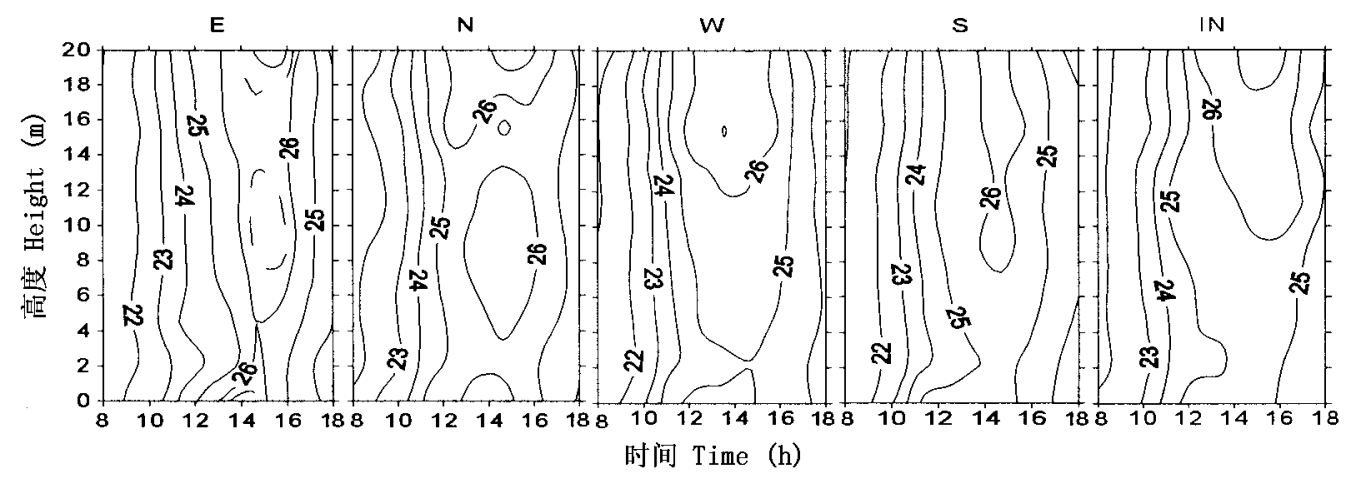

图 3 湿热季林窗边缘及林内树表温时间变化

$\mathrm{E}:$ 东侧 $; \mathrm{N}:$ 北侧 ; W : 西侧 $; \mathrm{S}:$ 南侧 $; \mathrm{IN}:$ 林内

Fig. 3 Temporal variation of trunk surface temperature at the edge of gaps and in the interior of the forest in the hot-wet season $\mathrm{E}:$ East edge ; N : North edge ; W : West edge ; S : South edge ; IN : Interior of forest 
为中心形成表面温度高值区,温度最高值分别为 $27.2^{\circ} \mathrm{C}$ ( 16 时) 和 $28.6^{\circ} \mathrm{C}$ ( 15 时)。另外由于湿热季 太阳高度较高，太阳光能够直接照射到树干下部，同 时也因为受林窗边缘地表温的影响，在东侧和北侧 树干基部附近 $(0 \mathrm{~m})$ 也形成了表面温度高值区。林 窗南侧和西侧边缘树表温仍是上高下低分布型, 最 大值都出现在树干上部, 分别为 $27.2^{\circ} \mathrm{C}$ ( 15 时) 和 $27.5^{\circ} \mathrm{C}$ ( 12 时)。

3.1.2 林内树表温的时空分布 雾凉季和湿热季 的林内树表温的时空变化 (图 2 3) 与已有研究报 道的规律相同（张一平等，2000，2001）:上午树表温 的垂直变化不明显，下午，受太阳直接辐射的树冠层 温度最高，热量下传，形成树表温的逆温分布。其温 度最大值雾凉季为 $17.9^{\circ} \mathrm{C}$, 湿热季为 $28.5^{\circ} \mathrm{C}$, 均于 15 时出现在树干 $20 \mathrm{~m}$ 处。

\section{2 林窗边缘与林内树表温差异特征}

在雾凉季, 4 方位林窗边缘各高度树干表面温 度普遍高于林内, 特别是上午 12 时后, 东侧和北侧 (图 4) 林窗边缘表现尤为突出,形成了树表温差值 的高值区:林窗边缘东侧差值的高值区有两处, 分别 出现在树干 $20 \mathrm{~m}$ 和 $8 \mathrm{~m}$ 处, $20 \mathrm{~m}$ 处最大差值为 $1.9^{\circ} \mathrm{C}$ ( 15 时) ,略高于 $8 \mathrm{~m}$ 处的差值最大值 $1.5^{\circ} \mathrm{C}$ (15 时) ;林窗边缘北侧 $2 \sim 14 \mathrm{~m}$ 均可看作高值区， 在 $8 \mathrm{~m}$ 处出现最大差值 $2.0^{\circ} \mathrm{C}$ ( 13 时)。西侧和南 侧 ( 图略) 各高度树表温与林内的差值不大。
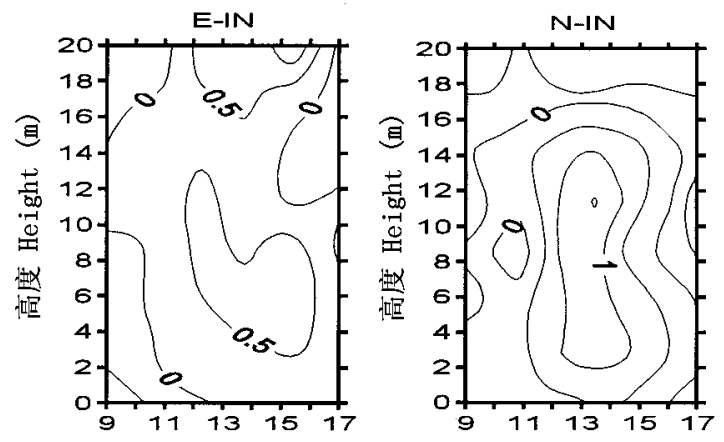

时间 Time (h)

图 4 雾凉季林窗东侧、北侧边缘与林内树表温差的时空分 布

E - IN : 东侧 - 林内 ; N - IN : 北侧 - 林内

Fig. 4 Temporal and spatial distribution of differences of trunk surface temperature between east and north edges of gap and interior of forest

E - IN : East edge minus interior ; N - IN :North edge minus interior

而在湿热季 (图略),4 方位林窗边缘各高度树 干表面温度, 只是在太阳高度角较大、太阳辐射较强
的 $12 \sim 15$ 时，在部分高度树干上高于林内树干表面 温度, 并形成差值高值区。差值高值区现象仍是在 东侧和北侧边缘表现明显。东侧的差值高值区出现 在树干 $8 \mathrm{~m}$ 附近, 差值最大值为 $1.7^{\circ} \mathrm{C}$ ( 15 时) ; 北 侧的差值高值区有两处：树干 $4 \mathrm{~m}$ 附近和树干上部， $4 \mathrm{~m}$ 附近的差值高值区最大差值为 $1.3^{\circ} \mathrm{C}$ ( 14 时), 低于树干上部的差值最大值 $1.7^{\circ} \mathrm{C}(12$ 时, $16 \mathrm{~m})$ 。 西侧和南侧的差值高值区现象表现不太明显。

季节雨林林窗东侧和北侧边缘树表温与林内树 表温的差值在一定高度出现高值区的现象, 与张一 平等 $(2000,2001)$ 在同一地区对树高约为 $18 \mathrm{~m}$ 的 次生林林窗研究所得结果一致。但由于季节雨林林 窗边缘的树木较高，一日当中，只有太阳高度角较大 时, 太阳光才能直接照射到林窗内, 使得季节雨林林 窗边缘树表温差值高值区所在位置的高度高于次生 林林窗。同时, 高大树木对太阳辐射的遮挡作用, 又 造成季节雨林林窗边缘树表温差值高值区的热力效 应强度小于次生林林窗。这说明林窗边缘壁面的热 力效应除与太阳高度角、太阳辐射的时间长短和强 度有关外，林窗边缘树木高度也是不可忽视的因子。

3.3 不同热力作用面的表温差异

为定量比较季节雨林林窗区域不同热力作用面 热力效应的差异, 取林内地表面温度的平均值为基 准 求算其他热力作用面表面温度与其的差值, 对不 同热力作用面的热力特征进行分析。

3.3.1 林窗边缘林墙壁面雾凉季上午 12 时前, 4 方位林窗边缘各高度树表温均低于林内地表温 (图 5 ) , 其绝对差的最大值都出现在林缘壁面的下部, 表明上午林内地表面的热力效应大于林缘壁面。12 时后, 随着太阳辐射的增强, 差值逐渐由负转正。到 下午 13 时, 除西侧边缘部分高度树表温略低于林内 地表温之外, 其他方位林窗边缘各高度树表温都已 经超过林内地表温。13 时后,4方位林窗边缘各高 度树表温与林内地表温之间的差异进一步增大, 并 先后在不同高度形成差值高值区。东侧的差值高值 区出现在树干 $8 \mathrm{~m}$ 和 $20 \mathrm{~m}$ 处, $8 \mathrm{~m}$ 处的差值最大值 为 $1.5^{\circ} \mathrm{C}$ ( 15 时), $20 \mathrm{~m}$ 处的差值最大值为 $2.5^{\circ} \mathrm{C}$ (15 时)。北侧在树干 $12 \mathrm{~m}$ 处形成差值高值区, 最 大差值为 $2.2^{\circ} \mathrm{C}(13$ 时)。西侧和南侧在树干上部 形成差值高值区, 但差值最大值小于东侧和北侧, 西 侧差值最大值为 $1.2^{\circ} \mathrm{C}(13$ 时, 20 m) , 南侧则为 $0.8^{\circ} \mathrm{C}(15$ 时, $16 \mathrm{~m})$ 。 


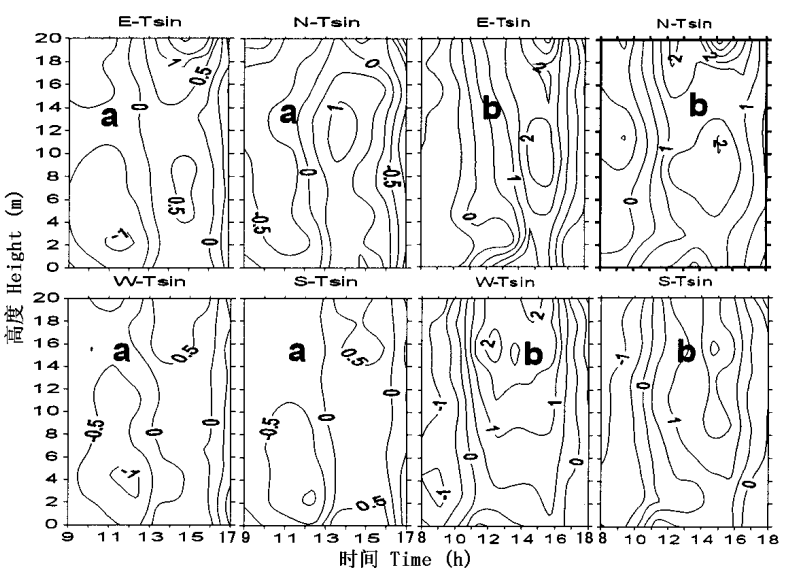

图 5 雾凉季和湿热季 4 方位林窗边缘树表温与林内地表 温差的时空分布

$\mathrm{a}$ : 雾凉季 ; b : 湿热季 ; E - T sin :东侧 - 林内 ; $\mathrm{N}-\mathrm{T} \sin$ : 北侧 - 林内 ; $\mathrm{W}-\mathrm{T} \sin$ :西侧 - 林内 $; \mathrm{S}-\mathrm{T} \sin$ :南侧 - 林内

Fig. 5 Temporal and spatial distribution of surface temperature difference between trunks at four azimuths edge of gap and soil surface in the interior of forest in cool-fog and hot-wet season a : Cool-fog season ; b : Hot-wet season ; E - Tsin : East minus interior ; $\mathrm{N}-\mathrm{T} \sin :$ North minus interior ; $\mathrm{W}-\mathrm{T} \sin : \mathrm{W}$ est minus interior ; $\mathrm{S}-\mathrm{T} \sin$ : South minus interior

在湿热季,由于雾消散时刻较雾凉季早, 因而在 上午 11 时, 4 方位林窗边缘各高度树表温与林内地 表温差值就逐渐由负转正。并且随着太阳高度角的 增大、太阳辐射的增强，差值进一步增大，先后在 4 方位林窗边缘不同高度树干表面都形成差值高值 区。东侧差值高值区出现在树干 $8 \sim 12 \mathrm{~m}$ 和 $20 \mathrm{~m}$ 处, 最大差值均为 $3.3^{\circ} \mathrm{C}(15$ 时, $12 \mathrm{~m}$ 和 16 时, 20 $\mathrm{m})$ 北侧出现在 $8 \mathrm{~m}$ 和 $20 \mathrm{~m}$ 处, 差值最大为 $3.9^{\circ} \mathrm{C}$ $(15$ 时 $20 \mathrm{~m})$ 。西侧和南侧的差值高值区现象也很 明显, 差值最大值分别为 $3.5^{\circ} \mathrm{C}(12$ 时, $16 \mathrm{~m})$ 和 $2.6^{\circ} \mathrm{C}(15$ 时, $16 \mathrm{~m})$ 。

这一结果与张一平等 (2000,2001) 对西双版纳 次生林林窗边缘壁面研究的结果相一致, 但由于季 节雨林林窗边缘树木高度高于次生林，受其影响，使 得季节雨林林窗边缘树表温与林内地表温差值高值 区的位置高于次生林林窗, 而强度小于次生林林窗。 季雨林林窗边缘树表温与林内地表温差值高值区的 存在，进一步说明了林窗边缘壁面具有不可忽视的 热力作用。

3.3.2 林冠面 由于条件所限, 未能对林冠面的表 面温度进行直接观测, 以 4 方位林窗边缘和林内林 冠下表面温度的平均值代表林冠面的热力效应进行 分析。由图 6a 可见,雾凉季上午林冠下表面温度低 于林内地表面, 说明上午林冠面热力作用小于林内
地表面;而下午除 17 时外,林冠下表面温度均高于 林内地表温, 最大差值为 $2.6^{\circ} \mathrm{C}(15$ 时)。表明当林 冠面接受到太阳直接辐射后, 升温速度快于林内地 表面,下午绝大部分时间的热力效应强于林内地表 面。

湿热季 (图 6b) 与雾凉季情况相似, 但由于湿热 季雾散日出较早,太阳光照时间较长, 因而在昼间的 大部分时间内 (11 17 时)，林冠下表面温度高于林 内地表面,热力效应强于林内地表面。

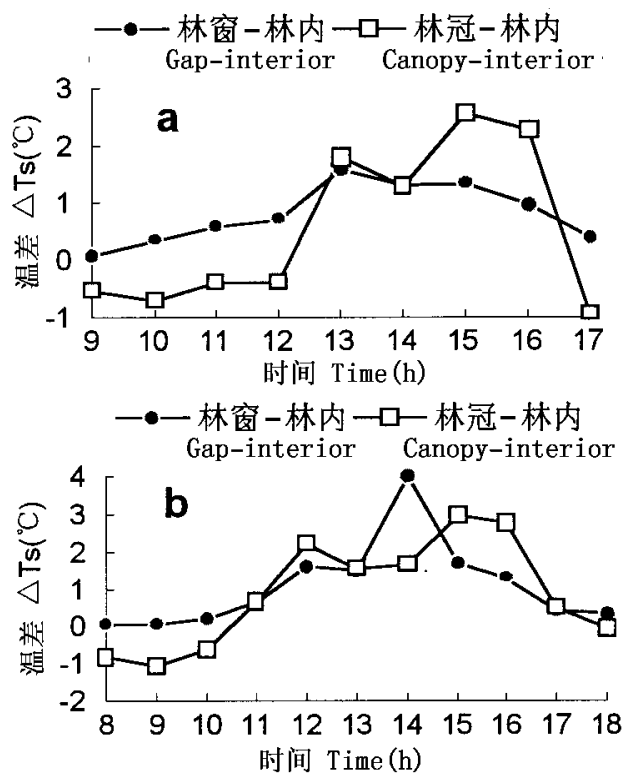

图 6 雾凉季和湿热季林窗地表面、林冠面与林内地表面温 差

$\mathrm{a}$ : 雾凉季 $; \mathrm{b}:$ 湿热季

Fig. 6 Difference of surface temperature between soil surface of gaps and in the interior of the forest and between canopy surface and soil surface in the interior of forest a : Cool-fog season ; b : Hot-wet season

3.3.3 林窗地表面从图 6 可知, 在雾凉季 (图 6a) 和湿热季 (图 6b) 昼间, 林窗地表温均高于林内 地表温,最大差值分别为 $1.6^{\circ} \mathrm{C}$ (13 时) 和 $4.0^{\circ} \mathrm{C}(14$ 时)。表明雾凉季和湿热季昼间林窗地表面的热力 作用大于林内地表面。这主要是因为林窗地表面没 有树冠的遮蔽, 能够接受到较多的太阳辐射, 获得较 多的热量, 因而表现出更强的热力效应。

另外, 从图 6 还可看出，林冠下树表温和林窗地 表温与林内地表温的差值时间变化存在时间差。雾 凉季林冠下树表温与林内地表温最大差值出现在 15 时, 比林窗地表温与林内地表温最大差值 (出现 在 13 时)滞后约 2 个小时; 湿热季林冠下树表温与 林内地表温最大差值仍出现在 15 时, 但林窗地表温 
与林内地表温最大差值出现在 14 时, 因此, 滞后约 1 小时。

3.3.4 林窗区域各热力作用面热力效应的比较 为了进一步比较林窗区域不同热力作用面的热力效 应，求算了各热力作用面的表面温度的平均值，并进 行了方差分析。其中, 林冠下树表温为 4 方位林窗 边缘树冠下和林内林冠下树表温平均值; 林窗地表 温为林窗中央和 4 方位实际林窗边缘地表温的平均 值:林缘树表温为 4 方位林窗边缘各高度 $(0.5 \sim 20$ m) 树表温的平均值。

比较各热力作用面的平均表温 (表 1 ) 可以看 出,在雾凉季和湿热季不同时段各热力作用面的热 力效应强度的变化规律十分相似。上午为林窗地表 面 > 林内地表面 $\geqslant$ 林冠下方表面 > 林窗边缘壁面, 而下午是林冠下方表面 $\geqslant$ 林窗地表面 $>$ 林窗边缘壁 面 > 林内地表面, 并且, 下午各热力作用面的热力效 应强度均大于上午。

虽然湿热季各热力作用面不同时段的平均表面 温度均高于雾凉季, 但是从下午与上午的表面温度
差来看, 湿热季与雾凉季相差不大, 具有相近的增温 率。另外, 比较各热力作用面的增温率, 显示出受太 阳辐射影响最大的林冠面增温速率最大, 热力效应 的变率最大;而林缘壁面的增温速率与林窗地面增 温速率相近,超过了林内地表面。

从方差分析结果来看 (表 2 ) ,无论是雾凉季还 是湿热季, 林窗区域不同热力作用面之间的表面温 度均没有显著性差异, 说明昼间林窗边缘壁面具有 与其他热力作用面同等水平强度的热力效应。

\section{4 小结}

通过对西双版纳热带季节雨林林窗的小气候要 素的观测，初步得到以下结果：

1 ) 在西双版纳雾凉季和湿热季, 季节雨林林窗 边缘树干表面温度均在某一高度 (其高度随方位存 在差异) 出现最大值, 显示了林窗边缘壁面的热力 效应;由于林窗边缘树木高度的影响, 高值区出现的 位置高于同一地区的次生林林窗，但高值区热力效 应强度低于次生林林窗。林窗边缘与林内树干表面

表 1 不同热力作用面表面温度平均值 $\left({ }^{\circ} \mathrm{C}\right)$

Table 1 Mean surface temperature of different thermal active surfaces

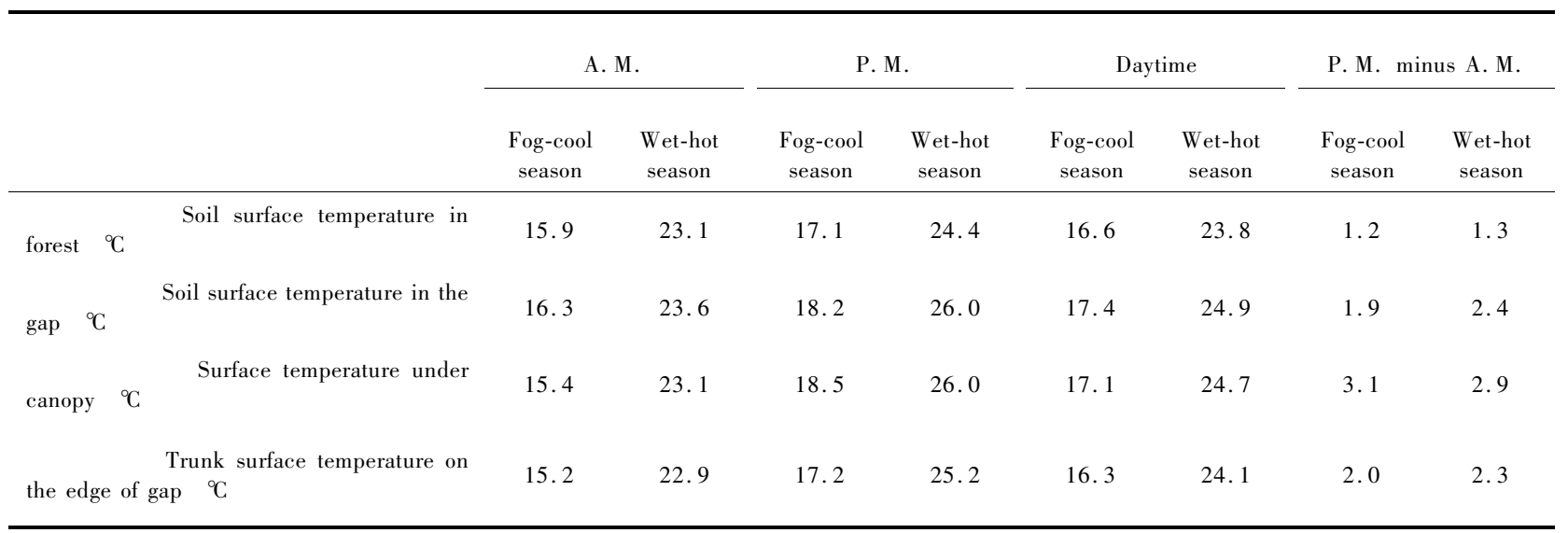

表 2 不同热力作用面表面温度平均值方差分析的 $\mathbf{F}$ 值和概率值

Table 2 F value and probability of differences of mean surface temperature of different thermal active surfaces

\begin{tabular}{|c|c|c|c|c|c|c|}
\hline $\begin{array}{l}\text { 季节 } \\
\text { Season }\end{array}$ & $\begin{array}{c}\text { 方差来源 } \\
\text { Source }\end{array}$ & $\begin{array}{l}\text { 偏差平方和 } \\
\text { Sum of squares }\end{array}$ & $\begin{array}{c}\text { 自由度 } \\
\mathrm{df}\end{array}$ & $\begin{array}{c}\text { 均方 } \\
\text { Mean square }\end{array}$ & $\begin{array}{c}\text { F 值 } \\
\text { F value }\end{array}$ & $\begin{array}{c}\text { 概率值 } \\
P\end{array}$ \\
\hline $\begin{array}{l}\text { 雾凉季 } \\
\text { Fog-cool } \\
\text { season }\end{array}$ & $\begin{array}{l}\text { 组间 Between types } \\
\text { 组内 Within types } \\
\text { 总方差来源 Total }\end{array}$ & $\begin{array}{r}2.033 \\
9.373 \\
11.406\end{array}$ & $\begin{array}{c}3 \\
8 \\
11\end{array}$ & $\begin{array}{l}0.678 \\
1.172\end{array}$ & 0.578 & 0.645 \\
\hline $\begin{array}{l}\text { 湿热季 } \\
\text { Wet-hot } \\
\text { season }\end{array}$ & $\begin{array}{l}\text { 组间 Between types } \\
\text { 组内 Within types } \\
\text { 总方差来源 Total }\end{array}$ & $\begin{array}{l}2.137 \\
10.6 \\
12.737\end{array}$ & $\begin{array}{c}3 \\
8 \\
11\end{array}$ & $\begin{array}{l}0.712 \\
1.325\end{array}$ & 0.538 & 0.700 \\
\hline
\end{tabular}


温度差值的高值区出现情况也有同样规律。说明林 窗边缘壁面的热力效应除与太阳高度角、太阳辐射 的时间长短和强度及季节有关之外，林窗边缘树木 高度也是不可忽视的因子。

2) 通过各热力作用面表面温度平均值的比较 及方差分析可以看出，林窗边缘壁面具有与林窗区 域其他热力作用面同等水平强度的热力效应，其热 力作用在昼间部分时候甚至强于林内地表面。这一 结果再一次证明林窗边缘壁面是林窗区域除林冠 面、林窗地表面和林内地表面之外的，一个新的、重 要的热力作用面。

3 ) 林窗边缘壁面相当强度热力效应的存在, 势 必导致林窗区域的热力传输差异, 影响林窗的热力 状况，这或许会直接对林窗内种子萌发、幼苗的生存 生长以及植物的光合作用、蒸腾作用等一系列生理 生长过程产生重要的作用,最终影响林窗的更新。

致谢 本研究得到了中国生态系统研究网络西双版 纳热带森林生态站的大力支持，在观测中使用了该 站的部分观测仪器, 该站的段文平、刘梦楠等同志参 加了观测,在此表示感谢。

\section{参考文献}

任泳红, 曹敏, 唐建维, 唐勇, 张建侯, 1999. 西双版纳季节雨 林与橡胶多层林调落物动态的比较研究. 植物生态学 报, 23(5) : 418 425

王进欣, 张一平, 马友签, 刘玉洪, 李佑荣, 1999. 干季晴天橡 胶林林窗温度剖线分布特征. 生态科学, 18(3): 7 10

王正非, 朱廷曜, 朱劲伟, 崔启武, 1985. 森林气象学. 北京: 中 国林业出版社, 236 252

翁笃鸣, 陈万隆, 沈觉成, 高家表, 1981. 小气候和农田小气 候. 北京: 农业出版社, 175 177

张克映, 1966. 滇南气候的特征及形成因子的初步分析. 气象 学报, $\mathbf{3 3}(2): 210 \sim 230$

藏润国, 刘静艳, 董大方, 1999. 林隙动态与森林生物多样性. 北京: 中国林业出版社, $51 \sim 68$

张一平, 刘玉洪, 马友針, 王进欣, 1999. 西双版纳热带次生林 林窗干热季气温分布特征的初步分析. 植物资源与环 境, $8(2): 7 \sim 12$

张一平, 王进欣, 马友睡, 刘玉洪, 2000. 西双版纳热带次生 林林窗边缘树表温的时空分布. 北京林业大学学报, 22 (3) : $8 \sim 13$
张一平, 王进欣, 马友針, 2001. 热带次生林林窗不同热力作 用面特征分析. 应用生态学报, 12 (2) : 179 184

Bazzaz F A and Wayne P M, 1994. Coping with environmental heterogeneity: the physiological ecology of tree seedling regeneration across the gap-understory continuum. In: Caldwell M M, Pearcy R W(eds. ), Physiological Ecology-A Series of Monographs Texts and Treatises. San Diego: Academic Press, $349 \sim 390$

Brokaw N V L, 1985. Treefalls, regrowth and community structure in tropical forests. In: Pickett S T A, White P S (eds.), The Ecology of Nature Disturbance and Patch Dynamics. New York: Academic Press, $53 \sim 69$

Brokaw N V L and Scheiner S M, 1989. Species composition in gaps and structure of a tropical forest. Ecology, 70(3): 538 $\sim 541$

Brown N, 1993. The implications of climates and gap microclimate for seedling growth condition in a Bronean lowland rain forest. Journal of Tropical Ecology, 9: 153 168

Canham C D, Denslow J S, Platt W J, Runkle J R, Spies T A and White P S, 1990. Light regimes beneath closed canopies and tree-fall gaps in temperate and tropical forest. Canada Journal of Forest Resource, 20: 620 631

Clark D B, 1990. The role of disturbance in the regeneration of neotropical moist forest. In: Bawa K S, Hadley M (eds.), Reproductive Ecology of Tropical Forest Plants. Paris: MAB-UNESCO Series, 7:291 315

Connell J H, 1989. Some processes affecting the species composition in forest gaps. Ecology, 70(3):560 562

Denslow J S, 1980. Gap partitioning among tropical rainforest trees. Biotropica, 12:47 $\sim 55$

Runkle J R, 1982. Patterns of disturbance in some old-growth mesic forests of eastern North America. Ecology, 62(4): $1041 \sim 1051$

Schupp E W, Home H F, Augspurger C K and Levey D J, 1989. Arrival and survival in tropical treefall gaps. Ecology, 70(3): $562 \sim 564$

Watt A S, 1947. Pattern and process in the plant community. Journal of Ecology, 35: $1 \sim 22$

Whitmore T C, 1978. Gaps in the forest canopy. In: Tomlison P B, Zimmermann M H (eds.), Tropical Trees as Living Systems. Cambridge: Cambridge University Press, 639 655

Whitmore T C, 1989. Canopy gaps and the two major groups of forest trees. Ecology, 70(3):536 538

Whitmore T C, 1990. An Introduction to Tropical Rain Forest. Oxford: Clarendon Press, $23 \sim 28,99 \sim 132$

\section{(责任编辑：闯文杰)}

